\title{
PEMILIHAN PERUSAHAAN OUTSOURCING UNTUK PEMBANGUNAN KAPAL BARU DENGAN METODE ANALYTICAL HIERARCHY PROCESS DI WILAYAH GRESIK, SURABAYA, SIDOARJO DAN MOJOKERTO
} (Studi Kasus : PT. Adiluhung Sarana Segara Indonesia)

\section{Choosing Outsourcing Fabricator for Building New Ship with Analytical Hierarchy Process Method at Gresik, Surabaya, Sidoarjo and Mojokerto (Case Study : PT. Adiluhung Sarana Segara Indonesia)}

\author{
Tristiandinda Permata ${ }^{1}$, Djauhar Manfaat ${ }^{1}$, dan Buana Ma'ruf ${ }^{2}$ \\ ${ }^{1}$ Institut Teknologi Sepuluh Nopember, Surabaya \\ ${ }^{2}$ Pusat Teknologi Rekayasa Industri Maritim, BPPT \\ Email : tristiandinda.permatahari@gmail.com
}

Diterima: 3 Oktober 2016; Direvisi: 25 Oktober 2016; Disetujui: 27 Oktober 2016

\begin{abstract}
Abstrak
Galangan kapal berlokasi di tepi pantai, padahal harga lahan di wilayah ini relatif mahal. Pada prakteknya, lahan galangan ini diperuntukkan proses produksi mulai dari fabrikasi, sub assembly, assembly hingga erection. PT. Adiluhung Sarana Segara Indonesia merupakan galangan kapal kelas menengah, namun memiliki lahan yang terbatas. Galangan ini sedang mendapatkan banyak order pada 2 (dua) tahun terakhir, sehingga melakukan perluasan lahan untuk memperlancar jalannya proses produksi. Hal ini perlu mempertimbangkan investasi biaya yang dibutuhkan. Sehingga dirumuskan salah satu metode untuk mengoptimalkan lahan galangan kapal agar dapat fokus pada inti bisnisnya, yaitu metode outsourcing yang menjadi trend industri saat ini. Metode cut material order memiliki alur proses fabrikasi dilakukan di perusahaan outsourcing, sehingga material yang tiba di galangan dalam kondisi siap assembly. Galangan hanya perlu menghitung dan mendesain bagian - bagian konstruksi yang dibutuhkan untuk dikirim ke perusahaan outsourcing. Metode pemilihan perusahaan outsourcing ini adalah dengan Analytical Hierarchy Process (AHP) untuk pemilihan alternatif perusahaan yang sesuai untuk diterapkannya cut material order. Kriteria dan subkriteria pada struktur AHP diperoleh dari identifikasi penelitian - penelitian sebelumnya terkait perusahaan outsourcing. Antar kriteria dan subkriteria dilakukan perbandingan berpasangan untuk mendapatkan alternatif yang sesuai, sehingga didapatkan perusahaan outsourcing yang dipilih pertama adalah PT. Gunawan Dianjaya Steel di Surabaya dengan nilai 0.519, PT. Ispatindo di Sidoarjo dengan nilai 0.260, PT. Indobaja Prima Murni di Gresik dengan nilai 0.136 dan PT. Peroni Karya Sentra di Mojokerto dengan nilai 0.085.
\end{abstract}

Kata kunci : lahan, fabrikasi, cut material order

\section{Abstract}

The shipyard is located on the beach, whereas the price of land is relatively expensive. In practice, this land for production process from fabrication, sub-assembly, assembly and erection. PT. Adiluhung Sarana Segara Indonesia is a middle-class shipyard, but has limited land. This shipyard getting a lot of orders in two (2) years latest, so to expand their land for running the production process. It is necessary to consider the investment costs required. Thus formulated one of the methods for optimizing land shipyards in order to focus on its core business, namely the method of outsourcing is a trend 


\begin{abstract}
industry now. Methods orders have cut material fabrication process is done in an outsourcing company, so that the material that arrived at the shipyard is ready for assembly. Shipyard just calculate and design parts of construction needed to be sent to the outsourcing company. The method of selecting an outsourcing company by the Analytical Hierarchy Process (AHP) for selection alternatives to suit the application of the cut material order. The criteria and sub-criteria in AHP structure obtained from the identification of latest researches related to the outsourcing company. Among criteria and sub-criteria pairwise comparisons conducted to obtain a suitable alternative, so we get the first selected outsourcing company is PT. Dianjaya Gunawan Steel in Surabaya with a value of 0519, PT. Ispatindo in Sidoarjo with a value of 0260, PT. Indobaja Prima Pure in Gresik with a value of 0.136 and PT. Peroni Karya Sentra in Mojokerto with a value of 0.085.
\end{abstract}

Keywords: land, fabrication, cut material order

\section{PENDAHULUAN}

Pembangunan suatu galangan kapal perlu diketahui terlebih dahulu tujuannya, apakah untuk dikembangkan atau pembangunannya memang pada lahan yang tidak dapat dikembangkan lagi, tentunya faktor - faktor penting harus dipertimbangkan. Melalui suatu analisis potensi pasar, persebaran pasar, keberadaan subkontraktor, pasar tenaga kerja, keperluan lingkungan sekitar, biaya untuk energi, dan ketersediaan biaya untuk pemeliharaan lahan juga ikut dipertimbangkan. Analisis ini tentunya juga mempertimbangkan geografi atau faktor wilayah seperti keberadaan laut dan terlindung dari laut, alam raya, rel dan transportasi air, keberadaan sekolah dan universitas teknik (Storch, 1995). Salah satu langkah memenuhi pertimbangan - pertimbangan tersebut adalah dengan menyediakan lahan yang cukup luas dan strategis untuk pembangunan kapal.

PT. Adiluhung Sarana Segara Indonesia, merupakan galangan kapal skala menengah yang berlokasi di Desa Ujung Piring, Kabupaten Bangkalan. Galangan kapal ini memiliki luas lahan $2097 \mathrm{~m}^{2}$ yang pada mulanya diutamakan menyediakan jasa reparasi dan perawatan kapal - kapal PT. Dharma Lautan Utama. Seiring dengan kemajuan fasilitas dan pengembangan manajemen, PT. Adiluhung Sarana Segara Indonesia juga melayani pembangunan kapal baru. Keterbatasan fasilitas dan lahan menjadi hambatan untuk dapat menyelesaikan pembangunan kapal ini dengan tepat waktu. Sehingga, galangan ini memilih untuk memperluas area pembangunan kapal dengan membeli lahan di sekitar pantai. Mahalnya harga tanah ini menjadikan galangan ini harus mengeluarkan biaya investasi lebih banyak lagi.

Wilayah sekitar galangan kapal PT. Adiluhung Sarana Segara Indonesia, meliputi Gresik, Mojokerto, Surabaya dan Sidoarjo, hanya terdapat dua perusahaan penyedia material pelat marine use untuk kapal. Kedua perusahaan ini berlokasi di Surabaya, sehingga belum terdapat perusahaan alternatif penyedia pelat baja lainnya. Untuk meningkatkan produktivitas galangan kapal juga diperlukan industri penyedia jasa pendukung pembangunan kapal secara outsourcing. Pekerjaan pendukung pembangunan kapal dikerjakan di luar galangan, sehingga galangan dapat benar-benar menjalankan inti bisnisnya, yaitu membangun kapal.

Paper ini membahas tentang penerapan pekerjaan fabrikasi yang dikerjakan secara outsourcing dengan wilayah Surabaya, Gresik, Sidoarjo dan Mojokerto. Pemilihan perusahaan outsourcing dengan metode Analytical Hierarchy Process (AHP) melalui identifikasi penelitian - penelitian sebelumnya terkait outsourcing. Sehingga, material yang tiba di galangan siap untuk dilanjutkan pada tahap assembly dan lahan yang digunakan untuk pekerjaan fabrikasi dapat digunakan untuk melakukan pekerjaan lainnya.

\section{KAJIAN PUSTAKA}

\section{Tinjauan Penerapan Cut Material Order}

Metode cut material order dilakukan untuk penghematan biaya pengadaan material khususnya material pelat. Alur produksi dalam metode cut material order dapat dilihat pada gambar berikut:

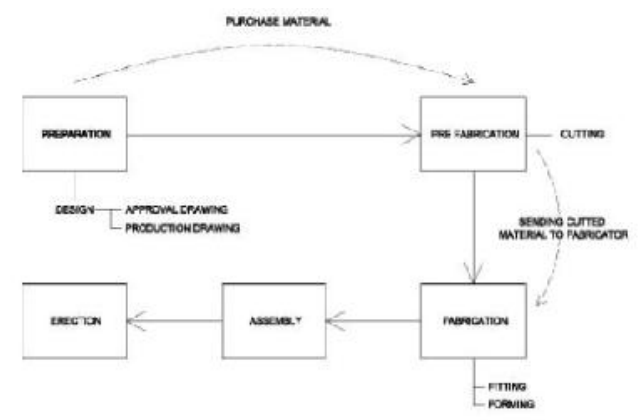

Gambar 1. Alur cut material order di PT.Meranti Nusa Bahari

Pada metode cut material order, galangan melakukan perhitungan kebutuhan pelat. Setelah kebutuhan pelat selesai dikalkulasi, galangan memesan material ke supplier di wilayah yang ditunjuk. Supplier kemudian mengirim material ke bengkel potong. Di bengkel potong, pelat dipotongi sesuai dengan gambar rencana potongan menjadi komponen pembentuk gading. Setelah selesai dipotongi, komponen tersebut dikemas berdasarkan penomorannya kemudian dikirim ke galangan. Material yang tiba di galangan berupa 
Pemilihan Perusahaan Outsourcing untuk Pembangunan Kapal Baru dengan Metode Analytical Hierarchy Process di Wilayah Gresik, Surabaya, Sidoarjo dan Mojokerto (Tristiandinda Permata, Djauhar Manfaat, Buana Ma'ruf)

komponen gading kemudian dirakit dalam proses fabrikasi dan seterusnya. Penelitian ini diaplikasikan pada pembangunan kapal tug boat di PT. Meranti Nusa Bahari yang berlokasi di Kalimantan Timur yang secara keseluruhan, dengan menerapkan metode ini, galangan dapat menghemat biaya pengadaan material dan pemotongan pelat sebanyak Rp.40.007.000,00 (Wimba Prambada, 2014).

Selain itu, PT. Dumas Tanjung Perak Shipyard yang berlokasi di Surabaya sejak Tahun 2013 telah menerapkan metode cut material order melalui outsourcing dengan perusahaan - perusahaan pemotongan pelat, blasting dan painting. Metode ini diterapkan karena keterbatasan lahan dan beban kerja yang tidak teratur, yaitu meningkat tajam di akhir tahun sehingga kemampuan fasilitas dan sumber daya manusia tidak mampu mengatasi beban kerja yang terlalu tinggi. Untuk menghindari molornya waktu delivery kapal yang berimbas pada denda dan reputasi galangan, sehingga dirumuskan metode cut material order yaitu, galangan membeli pelat di PT. Gunawan Dianjaya Steel sesuai dengan ukuran yang telah dipesan. Pelat - pelat ini diberikan treatment berupa blasting dan pengecatan shop primer di PT. Berdikari Sand Blasting, jika beban kerja tinggi pelat - pelat ini juga diberikan perakuan demikian di PT. Safinah Laras Persada, sehingga dapat dikerjakan secara parallel untuk lebih menghemat waktu. Pelat yang telah di blasting dan dicat shop primer selanjutnya dipotong sesuai dengan cutting plan di PT. Mitra Bahtera, sebagaimana gambar berikut:

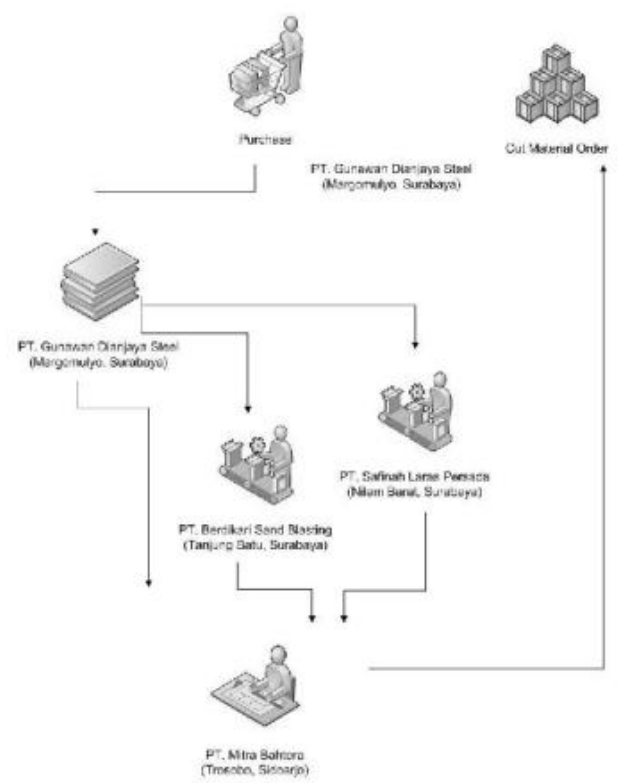

Gambar 2. Alur cut material order di PT.Dumas Tanjung Perak Shipyard
Pengecekan pekerjaan untuk kontrol kualitas dilaksanakan dengan mengirimkan personal bagian Quality Control dari pihak PT. Dumas Tanjung Perak Shipyard ke PT. Mitra Bahtera. Pelat yang sudah dipotong dikirimkan ke PT. Dumas Tanjung Perak Shipyard dan dilakukan pengecekan ulang.

\section{Metode Outsourcing}

Menurut O'Brien dan Marakas (2010) dalam bukunya "Introduction to Information Systems", istilah outsourcing dalam arti luas adalah pembelian sejumlah barang atau jasa yang semula dapat dipenuhi oleh internal perusahaan tetapi sekarang dapat memanfaatkan mitra perusahaan sebagai pihak ke tiga. Kaitannya dengan galangan kapal dalam proses pengadaan material yang telah terpotong (cut material order), outsourcing pada mulanya di PT. Adiluhung Sarana Segara Indonesia adalah berupa pengadaan manpower untuk melakukan proses fabrikasi dan $s u b$ assembly di galangan dengan memanfaatkan fasilitas galangan, namun dengan metode cut material order memberikan alternatif pekerjaan fabrikasi dilakukan di perusahaan fabrikator baja sehingga lahan pekerjaan dan fasilitas di galangan dapat dimanfaatkan untuk pekerjaan lain untuk bangunan baru maupun reparasi. Jadi, outsourcing adalah pemberian pekerjaan yang tidak bersifat rutin (temporer) dan bukan inti pekerjaan di sebuah organisasi atau perusahaan ke pihak lain atau pihak ke tiga.

Kriteria pemilihan perusahaan outsourcing di wilayah Gresik, Surabaya, Sidoarjo dan Mojokerto pada penelitian ini diambil dari beberapa penelitian sebelumnya terkait outsourcing, sehingga didapatkan kriteria dan sub kriteria untuk memperoleh alternatif yang sesuai.

Paper Outsourcing yang diterbitkan oleh Sekolah Tinggi Program Pendidikan Manajemen menyatakan bahwa faktor - faktor yang menjadi pertimbangan dalam pemilihan provider jasa tenaga outsource berdasarkan hasil survei adalah harga menjadi faktor utama dalam pemilihan partner outsourcing (22.62\%). Sedangkan reputasi yang baik dari provider outsource menempati posisi kedua yaitu sebesar $21.43 \%$. Untuk tenaga outsource yang dimiliki sesuai dengan kebutuhan perusahaan (19.05\%), pengetahuan provider outsource terhadap proses bisnis perusahaan $(11.90 \%)$. Pengalaman sebelumnya menempati posisi kelima dalam pemilihan partner outsourcing $(10.71 \%)$, diikuti oleh stabilitas provider outsource $(8.33 \%)$ dan lainnya sebesar $5.95 \%$. Adapun faktor-faktor lainnya adalah pemenuhan persyaratan ketentuan tenaga kerja dan penyerapan tenaga terdekat dengan unit kerja.

Priandoyo dalam jurnalnya berjudul 'Risk management in information technology outsourcing, Proceeding on Information System National 
Conference' menyatakan bahwa keputusan untuk mengambil outsourcing tidak hanya bergantung dengan biaya yang harus dikeluarkan, paling tidak ada empat elemen yang harus diperhatikan saat membuat keputusan, yaitu tingkat layanan dan harga (Service levels and pricing), kontrak dan hubungan kerja (Contract and relationship), kepuasan pelanggan (Customer satisfaction) dan tujuan strategis.

Gabriel Giertl, Marek Potkany dan Milos Gejdos dalam penelitiannya 'Evaluation of Outsourcing Efficiency Through Costs For Its Use' menyatakan bahwa upaya pengurangan biaya untuk proses tertentu dalam sebuah perusahaan mengarah ke tanggung jawab mereka sebagai penyedia jasa eksternal. Namun demikian, harga harus menjadi salah satu faktor penting, selain itu juga berorientasi pada bisnis inti, transfer resiko, kualitas produk meningkat dan ahli pengetahuan akuisisi dengan manajemen proses dukungan. Resiko yang paling umum dalam hal pengalaman perusahaan tampaknya bukan menjadi permasalahan utama.

Silvana Zhezhova, Goran Demboski dan Vlatko Panov dalam penelitiannya 'Optimization of technological process of cutting by use of software applications for cut order planning menyatakan bahwa cut order plan' pada industri garmen harus mempertimbangkan banyak faktor penting seperti harga penjualan, tingkat persediaan, bahan baku, dan ketersediaan tenaga kerja dan peralatan. Berbagai ukuran, gaya, kain dan warna menambah variabel permasalahan. Menambah kompleksitas dan dengan demikian berpotensi meningkatkan total biaya produksi, ketepatan ukuran, dan kebutuhan untuk memenuhi tuntutan konsumen.

Dari penelitian - penelitian tersebut didapatkan faktor - faktor pemilihan perusahaan outsourcing yang digunakan pada penelitian ini, yaitu harga produk, kualitas produk, kualitas bahan baku, ketepatan waktu produksi, layanan asuransi produk, produk terstandarisasi, reputasi perusahaan, kualifikasi SDM, kemudahan akses, fasilitas produksi, kapasitas produksi, dan pengalaman sebelumnya dengan perusahaan tersebut.

\section{Pemilihan Perusahaan Outsourcing}

Perusahaan outsourcing pada penelitian ini berlokasi di wilayah Surabaya, Sidoarjo, Mojokerto dan Gresik. Perusahaan yang diidentifikasi dengan faktor - faktor tersebut memiliki kesamaan dalam hal material dasar pembuatan produk mereka, yaitu scrap, pig iron, besi spons dan hot bricket iron.

Perusahaan yang dipilih untuk Surabaya adalah PT. Gunawan Dianjaya Steel dengan produk baja marine use, Sidoarjo adalah PT. Ispatindo dengan produk wire rod, Mojokerto adalah PT. Peroni Karya Sentra dengan produk stainless steel fitting dan Gresik adalah PT. Indobaja Prima Murni dengan produk profil untuk industri otomotif.

Pemilihan perusahaan ini menggunakan metode Analytical Hierarchy Process (AHP), yaitu suatu metode analisis yang digunakan untuk membuat suatu model permasalahan yang tidak mempunyai struktur, serta dapat digunakan untuk memecahkan masalah yang bersifat kuantitatif dan masalah yang memerlukan pendapat (judgement). Penyelesaian masalah dalam metode AHP adalah dengan menyusun hirarki AHP terlebih dahulu dengan struktur sebagai berikut:

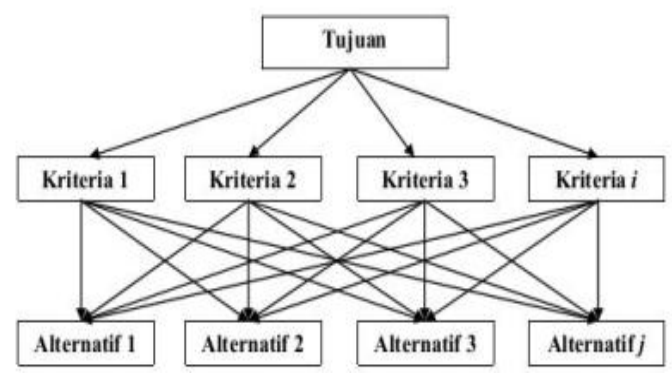

Gambar 3. Hirarki AHP

Gambar 3 menunjukkan hirarki AHP yang ditentukan terlebih dahulu sebelum melakukan perangkingan. Antar kriteria dan subkriteria dilakukan perbandingan berpasangan sehingga didapatkan eigen vector untuk menilai tiap alternatif.

Pada penelitian ini terdapat dua kriteria, yaitu produk dan perusahaan yang masing - masing memiliki subkriteria. Kriteria produk memiliki subkriteria harga, kualitas, kualitas bahan baku, ketepatan waktu produksi, asuransi dan kesesuaian dengan standar. Kriteria perusahaan memiliki subkriteria reputasi, kualifikasi SDM, kemudahan akses, fasilitas produksi, kapasitas produksi, dan pengalaman sebelumnya dengan perusahaan tersebut.

\section{METODOLOGI}

Permodelan penelitian ini (gambar 4) dilakukan dengan dengan wawancara dan pengisian kuisioner untuk responden di bidang akademisi, industri fabrikator baja, industri galangan kapal dan pemerintah dengan penyusunan kuisioner berdasarkan hirarki AHP (gambar 3) dengan tujuan untuk mendapatkan perusahaan outsourcing yang sesuai dalam penerapan cut material order di PT. Adiluhung Sarana Segara Indonesia. Kajian pustaka mencakup penelitian - penelitian sebelumnya terkait outsourcing, cut material order dan penelitian serupa. Wawancara dengan beberapa sumber juga diperlukan untuk mendapatkan kondisi lapangan. 
Pemilihan Perusahaan Outsourcing untuk Pembangunan Kapal Baru dengan Metode Analytical Hierarchy Process di Wilayah Gresik, Surabaya, Sidoarjo dan Mojokerto (Tristiandinda Permata, Djauhar Manfaat, Buana Ma'ruf)

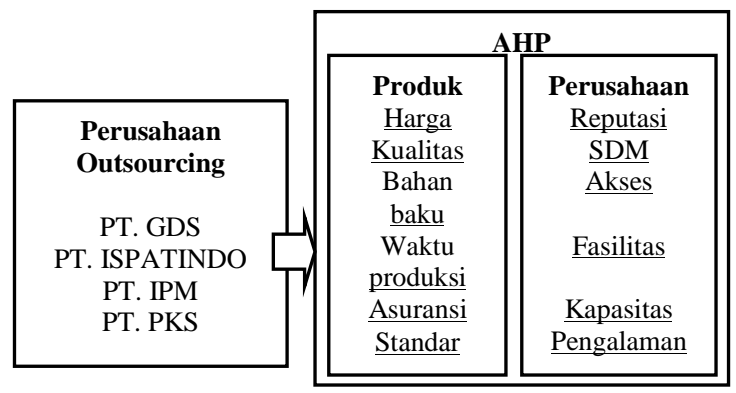

Gambar 4. Model penelitian

Hirarki AHP selanjutnya digunakan sebagai dasar perhitungan perbandingan berpasangan sebagaimana tabel 1 berikut:

Tabel 1. Matriks perbandingan berpasangan

\begin{tabular}{|c|c|c|c|c|}
\hline CTQ'S & $\begin{array}{c}\text { Kemudahan } \\
\text { Akses }\end{array}$ & $\begin{array}{c}\text { Ketepatan } \\
\text { waktu } \\
\text { produksi }\end{array}$ & $\begin{array}{c}\text { Kualifikasi } \\
\text { SDM } \\
\text { tinggi }\end{array}$ & $\begin{array}{c}\text { Kualitas } \\
\text { produk } \\
\text { baik }\end{array}$ \\
\hline $\begin{array}{c}\text { Kemudahan } \\
\text { Akses }\end{array}$ & 1 & & & \\
\hline $\begin{array}{c}\text { Ketepatan } \\
\text { waktu } \\
\text { produksi }\end{array}$ & & 1 & & \\
\hline $\begin{array}{l}\text { Kualifikasi } \\
\text { SDM tinggi }\end{array}$ & & & 1 & \\
\hline $\begin{array}{l}\text { Kualitas } \\
\text { produk baik }\end{array}$ & & & & 1 \\
\hline
\end{tabular}

Tabel 1 tersebut menunjukkan contoh matriks perbandingan berpasangangan antar subkriteria pada kriteria Perusahaan. Kolom yang bertemu dengan baris pada subkriteria yang sama akan bernilai 1 , selain itu maka nilainya merupakan perbandingan antara kolom dengan baris yang merupakan skala Saaty, sebagaimana tabel berikut:

\begin{tabular}{cc}
\hline Nilai & Tabel 2. Skala Saaty \\
\hline 1 & $\begin{array}{c}\text { Definisi } \\
\text { berpengaruh }\end{array}$ \\
\hline 2 & sangat tidak berpengaruh \\
\hline 3 & tidak berpengaruh \\
\hline 4 & sedikit berpengaruh \\
\hline 5 & Sedang atau netral \\
\hline 6 & sedikit berpengaruh \\
\hline 7 & berpengaruh \\
\hline 8 & sangat berpengaruh \\
\hline 9 & Amat sangat berpengaruh \\
\hline Sumber: Saaty & 2008
\end{tabular}

Nilai yang terdapat pada skala Saaty merupakan acuan untuk melakukan perhitungan pada tabel 1 . Responden memberikan penilaian terhadap perntanyaan - pertanyaan pada kuisioner berdasarkan skala Saaty tersebut, selanjutnya dilakukan perhitungan matriks berpasangan. Penilaian konsistensi responden dalam mengisi kuisioner juga diperhitungkan dalam batas ketidakkonsitensian yang tidak boleh lebih dari $10 \%$.

\section{HASIL DAN PEMBAHASAN}

Penelitian yang dilakukan untuk menentukan wilayah yang sesuai untuk penerapan cut material order pada pembangunan kapal baru di PT. Adiluhung Sarana Segara Indonesia yang berlokasi di Bangkalan dengan wilayah perusahaan outsourcing di Gresik, Surabaya, Sidoarjo dan Mojokerto ini mendapatkan hasil perhitungan matriks perbandingan berpasangan. Matriks ini menyesuaikan struktur pada hirarki AHP, yaitu antar kriteria, antar subkriteria dan antar alternative pada setiap subkriteria. Berikut adalah hasil perhitungan matriks perbandingan berpasangan:

Tabel 3. Matriks perbandingan berpasangan antar criteria

\begin{tabular}{cccc}
\hline Kiteria & Produk & Perusahaan & Eigen vector \\
\hline Produk & 0.78 & 0.78 & 0.78 \\
\hline Perusahaan & 0.22 & 0.22 & 0.22 \\
\hline TOTAL & 1.00 & 1.00 & 1.00 \\
\hline
\end{tabular}

Hasil pengisian kuisioner antar kriteria menghasilkan penilaian pada matriks perbandingan berpasangan sesuai pada tabel 3. Nilai tiap kriteria relative sama dikarenakan hanya ada dua kriteria yang dibandingka. Kriteria produk memiliki nilai eigen vector yang lebih tinggi daripada perusahaan, yaitu 0.78 , sedangkan kriteria perusahaan hanya 0.22 . Jadi, dapat diketahui bahwa galangan kapal memilih perusahaan outsourcing untuk penerapan cut material order ini lebih mengutamakan produk daripada perusahaan.

Masing-masing kriteria tersebut memiliki subkriteria yang juga diperhitungkan pada matriks berpasangan. Penilaian alternatif dilakukan dengan melakukan matriks berpasangan antar alternative pada tiap subkriteria, sehingga menghasilkan penilaian sebagai berikut:

\begin{tabular}{lcc}
\multicolumn{3}{l}{ Tabel 4. Hasil pernagkingan alternative } \\
\hline Perusahaan & Nilai & Peringkat \\
\hline PT. GDS & 0.497 & 1 \\
\hline PT. ISPAT & 0.261 & 2 \\
\hline PT. IPM & 0.139 & 3 \\
\hline PT. PKS & 0.082 & 4 \\
\hline
\end{tabular}

Hasil perangkingan tiap-tiap alternatif menunjukkan bahwa PT. Gunawan Dianjaya Steel yang berlokasi di Surabaya memiliki nilai tertinggi yaitu 0.497 , sehingga menempati peringkat pertama. Peringkat kedua adalah PT. Ispatindo yang berlokasi di 
Sidoarjo dengan nilai 0.261. Selanjutnya adalah PT. Indobaja Prima Murni yang berlokasi di Gresik dengan nilai 0.139 . Keempat adalah PT. Peroni Karya Sentra yang berlokasi di Mojokerto dengan nilai 0.082 .

\section{KESIMPULAN}

Berdasarkan analisis dan pembahasan yang dilakukan, maka dapat disimpulkan pemilihan perusahaan outsourcing dengan metode AHP menghasilkan prioritas pertama adalah PT. Gunawan Dianjaya Steel di Surabaya dengan nilai 0.519, ke dua adalah PT. Ispatindo di Sidoarjo dengan nilai 0.260 , ketiga adalah PT. Indobaja Prima Murni di Gresik dengan nilai 0.136, dan ke empat adalah PT. Peroni Karya Sentra di Mojokerto dengan nilai 0.085. Kriteria galangan dalam memilih perusahaan outsourcing adalah lebih cenderung menilai dari segi produk daripada perusahaan dengan eigen vector pada matriks perbandingan berpasangan pada kriteria produk adalah 0.78 dan kriteria perusahaan adalah 0.22 ;

Identifikasi faktor-faktor pemilihan perusahaan outsourcing adalah melalui rangkuman dari beberapa penelitian sebelumnya terkait outsourcing sehingga menghasilkan kriteria produk terbesar adalah harga dengan nilai 0.36 , kedua adalah kualitas produk yang baik dengan nilai 0.20 , ketiga adalah kualitas bahan baku dengan nilai 0.14 dan keempat adalah ketepatan waktu produksi dengan nilai 0.13 , kelima adalah ketersediaan asuransi dengan nilai 0.09 dan keenam adalah sertifikasi perusahaan dengan nilai 0.08 . Faktor perusahaan yang paling besar adalah reputasi perusahaan dengan nilai 0.27 , kedua adalah kualifikasi SDM dengan nilai 0.23 , ketiga adalah kemudahan akses dengan nilai 0.18 , keempat adalah fasilitas produksi dengan nilai 0.16 , kelima adalah kapasitas produksi dengan nilai 0.10 dan pengalaman sebelumnya dengan nilai 0.06 .

\section{DAFTAR PUSTAKA}

Gabriel, G, Potkany, M dan Gejdos, M. (2015). Evaluation of Outsourcing Efficiency Through Costs for Its Use, $4^{\text {th }}$ World Conference on Bussines, Economic And Management, Slovakia.

Marakas, GM dan Brien, O. (2010). Introduction to Information Systems, $15^{\text {th }}$ edition, McGraw- Hill, US.

Prambada, W. (2014). Analisis Teknis dan Ekonomis Penerapan Cut Material Order untuk Pembangunan Kapal Tug Boat di Kalimantan Timur sebagai Model Produksi Massal, Tugas Akhir Teknik Perkapalan ITS, Surabaya.

Priandoyo, Anjar. (2006). Risk Management in Information Technology Outsourcing, Proceeding on Information System National Conference, Bandung.
Saaty, Thomas. (2008). Decision Making with The Analytic Hierarchy Process, University of Pittsburgh, USA.

Sekolah Tinggi Program Pendidikan Manajemen, (2013). Paper Outsourcing, Jakarta.

Storch, R.L. (1995). Ship Production, Cornell Maritime Press, New Jersey.

Zhezhova, Silvana, Demboski, Goran dan Panov, Vlatko. (2000). Optimization of Technological Process of Cutting by Use of Software Applications for Cut Order Planning, Republic of Macedonia. 